\title{
Fattigdomens hjälplöshet - too hot to handle? Hur Astrid Lindgrens böcker om Madicken översatts i USA och Storbritannien
}

http://urn.kb.se/resolve?urn=urn:nbn:se:sbi-37

Citation: Nordic Journal of ChildLit Aesthetics, Vol. 2, 2011 DOI: 10.3402/ blft.v2i0.5840

Abstract: In children's literature, power relations are fundamentally assymetrical. This is furthermore accentuated in the process of translation where translation norms, social and cultural norms as well as the power game of adult authorities play a major part. The Swedish author Astrid Lindgren's ideology is based on the notion that no aspects of life should be hidden from the child, making her thematize as well as break taboos in her writing for children. There has been extensive research on Lindgren's authorship per se, but research on translations of her books seems to be limited. The fact that discussions on taboo elements in children's books in general, and Lindgren's source texts and target texts in particular are sparse indicates that this is a vast - and interesting - field still to be explored. This paper focuses on the American and British translations of Lindgren's Madicken (1960) and Madicken och Junibackens Pims (1976) in order to find out why and to what extent these books were censored in translation.

Keywords: children's literature, translation, norms, taboo elements, censorship

\section{Normer och ideologi}

Barnlitteratur är litteratur för och om barn som skrivs, publiceras och marknadsförs av vuxna. Denna makt-asymmetri förstärks ytterligare då översättning kommer med i bilden och förläggaren, redaktören eller översättaren bestämmer vad som skall inkluderas $i$ måltexten. Då en barnbok översätts får eventuella goda föresatser om att respektera det läsande barnet som en tänkande och kännande 
individ ofta ge vika för sociala normer och deras motsvarighet inom översättningsvetenskapen, översättningsnormer. Normsystemet har utvecklats av Gideon Toury och består av tre huvudbegrepp: preliminära normer, initiala normer och operationella normer som styr olika delar av översättningsprocessen. Den förstnämnda involverar förläggarens val om vilka texter som skall översättas; med hjälp av initiala normer gör sedan översättaren sitt första val om han skall producera en översättning som är anpassad till källtexten och dess normer ("adekvat" översättning) eller till måltexten och dess kultur ("acceptabel" översättning) medan operationella normer beskriver själva översättningsprocessen vad gäller ordval och formuleringar (Toury 1995, 58). Den belgiske forskaren Theo Hermans framhåller vidare att översättning i sig involverar minst tre olika normsystem: för det första källtextens normer, vidare det normsystem som för tillfället gäller i fråga om översättningar, och slutligen det normsystem som gäller litteraturen i målspråket. Här, menar han, rör det sig om ett socialt beteende som följaktligen inkluderar maktrelationer. Andrew Chesterman har för sin del lanserat begreppet expectancy norms, förväntningsnormer, vilket beskriver de förväntningar läsaren i målkulturen ställer på en text; hur texten skall se ut för att bli accepterad (Chesterman 1997, 64). Det är alltså ingen okomplicerad process det är frågan om då barnlitteratur skall översättas; varje översättning omfattar två språk och två kulturer med sina respektive olikheter i normer, värderingar och den yttre verkligheten med sina kulturspecifika drag som kan vara helt obekanta för det läsande barnet.

Under de senaste 30 åren har översättning av barnlitteratur varit föremål för akademisk forskning. Den svenske forskaren Göte Klingberg omnämns ofta som banbrytande i och med att han publiceradeen första samling av artiklar från IRSCLs symposium Children's books in translation 1978, samt en monografi om översättning av barnlitteratur 1986. Så sent som år 1993 noterade den finska barnlitteraturforskaren Riitta Oittinen i sin doktorsavhandling att det, globalt sett, forskats relativt lite i översättning av barnlitteratur och dess teoretiska aspekter. Idag är situationen långt bättre: bland de aspekter som forskningen omfattar kan nämnas läsbarhet (Puurtinen 1994), ideologiska faktorer (Thomson-Wohlgemuth 2003) samt översättning av bilderböcker (t.e.x Oittinen 2003). I en omfattande artikel från 2002 vidhåller Reinbert Tabbert att en av orsakerna till det växande intresset kunde vara antagandet om att barnböcker som översätts bygger broar kulturer emellan, vilket inbjuder till forskning. Vidare fäster han uppmärksamheten vid de utmaningar som är förknippade 
med översättning av barnlitteratur, och att översättningsprocessen påverkas av sociala, politiska och kulturella faktorer. Han påpekar också att polysystemteorin, enligt vilken barnlitteratur anses vara mindre prestigefylld och mindre värdefull än 'riktig' litteratur, gör att barnlitteratur med större sannolikhet utsätts för manipulering i översättning. Manipulering kan omfatta både ändringar samt förkortningar eller tillägg i texten, eller att till och med helt och hållet låta bli att publicera texten i översättning. Den finska forskaren Tiina Puurtinen skriver i en artikel från 1994 att översättare av barnböcker tillåts, och till och med förväntas, manipulera källtexten för att göra den acceptabel i målkulturens litterära system. Innan en bok ens når barnet har inte bara översättare utan också förläggare, redaktörer, lärare och föräldrar avgjort vad som är "bra" och "lämpligt" för barnet. Det föreligger diskrepans mellan det faktum att barnböcker översätts för att barnet skall få ta del av främmande kulturer och fenomen, och att just dessa element ofta stryks eller ändras i översättning. De stryks för att anpassa översättningen till målkulturen och dess normer som kan omfatta både sociala normer och förväntningsnormer.

Astrid Lindgrens Pippi Långstrump som utkom 1945 är kanske den bok som, på bekostnad av hennes övriga verk, varit föremål för mest diskussion och kontroverser både i sig och då det gäller forskningen om hur Lindgrens böcker översatts världen över. Ett av undantagen utgör Birgit Stolts artikel från 1978 där hon bland annat konstaterar att ett helt kapitel, kallat "Lisabet pillar in en ärta i näsan", i Madicken strukits i den amerikanska översättningen och att orsaken till detta torde vara att barnet som läser boken (med stor sannolikhet en flicka) inte skulle identifiera sig med flickorna i boken som både slåss och svär. I sin prisbelönta bok Comparative children's literature (2005) nämner Emer O'Sullivan Stolts artikel, men skriver också att i en senare amerikansk översättning från 1979 är kapitlet inkluderat. Översättningen hon nämner är de facto den brittiska översättningen där inga tabuelement eller annat som kunde tänkas väcka anstöt strukits.

I min kommande doktorsavhandling granskar jag hur normerna i USA, Storbritannien samt Tyskland inverkat på hur Astrid Lindgrens Madicken (1960) och Madicken och Junibackens Pims (1976) översatts i dessa målkulturer. Den amerikanska översättningen av den första boken om Madicken, Mischievous Meg, utkom 1962 medan den andra boken aldrig publicerades i översättning i USA. Det är värt att notera att det som inte översatts eller som utsatts för ändringar av ett eller annat slag, alltså det som osynliggjorts i måltexten, är av större intresse och mer relevant än det som förblivit ocensurerat. 
Överlag förefaller det som om tabuämnen i barnlitteratur och särskilt censur av barnlitteratur i översättning ännu idag är ett relativt osynligt ämne både i barnlitteraturforskning och till vardags.

Ideologi är kanske inte vad man i första hand associerar med barnlitteratur men kan också uppfattas i en vidare bemärkelse, utanför den politiska sfären. I sin artikel Ideology and the children's book från 1988 definierar barn- och ungdomslitteraturforskaren Peter Hollindale ideologi genom tre kategorier: den första består av författarens explicita sociala, politiska och moraliska värderingar; den andra är passiv ideologi som utgår från de värderingar som finns $i$ texten, och den tredje själva språket och hur ideologin är inskriven i ordvalet. Lindgrens ideologi i ordets vidaste mening grundar sig på respekt och kärlek för barnet som inte undervärderas och vars tankar och känslor tas på allvar, och bottnar troligtvis i hennes egen barndom som hon sagt var fylld av både trygghet och frihet. I sin biografi om Lindgren betonar Margareta Strömstedt (2003) vikten av sammanhållningen mellan arrendatorsfamiljen och tjänstefolket på Näs; de inte bara arbetade sida vid sida utan tillbringade också en stor del av sin knappt tilltagna fritid tillsammans. Detta kan ha bidragit till Lindgrens sociala medvetenhet och en insikt om att alla människor, särskilt de svaga och utsatta i samhället, är värdefulla och bör behandlas med respekt.

\section{Trygghet och tabuämnen}

De två böckerna om Madicken, Madicken (1960) och Madicken och Junibackens Pims (1976) skiljer sig i många hänseenden både från Lindgrens tidigare böcker och sinsemellan. Handlingen är förankrad i småstadsmiljö där barnkammaren i medelklasshemmet står för tryggheten och det statiska, medan världen utanför representerar äventyr och det dynamiska. Trots att föräldrarna också här håller sig i bakgrunden innehar de ändå en något mer framträdande roll än vad som brukar vara fallet i Lindgrens böcker; Madickens och Lisabets pappa, tidningsredaktören som kallas 'herrskapssocialisten' av invånarna i staden, uppmuntrar sina döttrar - och också deras mamma - till social medvetenhet, och drar sig inte för att diskutera svåra frågor med sina döttrar.

"Fattigdomens hjälplöshet, vad är det", frågar hon pappa. Och han förklarar, att om man är riktigt fattig, så är det som att vara bunden till händer och fötter, man kan inget göra. Man är alldeles hjälplös, när nånting händer, sjukdom eller annat som är svårt här i livet. (Lindgren 1976, 34) 
Engagemanget för de fattiga och utsatta har alltid haft sin givna plats i Lindgrens böcker men särskilt i Madicken och Junibackens Pims uttalas det mer direkt, och klyftan mellan samhällsklasserna både fördjupas och förmörkas. Det är kanske ingen tillfällighet att den var den sista boken Lindgren skrev innan hon på allvar gick med i den politiska debatten: boken publicerades hösten 1976 men hade skrivits och gått $\mathrm{i}$ tryck före Pomperipossadebatten våren 1976. I böckerna framstår Lindgrens ideologi att inte hemlighålla några som helst av livets mörka sidor från barnet som väldigt tydlig - ställvis rentav övertydlig - samtidigt som hon delar med sig av sina barndomsupplevelser. Madickens och Lisabets grannar, den alkoholiserade farbror Nilsson och hans familj samt Mia och Mattis, flickorna som är svältfödda på både mat och omsorg tillför den trygga medelklasstillvaron nya dimensioner. Då Mia och Mattis är på besök hos Madicken äter Mattis "så kolossalt att Mia skäms för henne" och Mia undrar om Mattis verkligen är hungrig än. Men det är inte Mattis - hon äter för att hon inte ska bli hungrig (Lindgren 1976, 136-137). Genom de olika socialklasserna och möten mellan dem kan Lindgren behandla svåra frågor i en utsträckning och på ett sätt som inte förekommit i hennes tidigare realistiska berättelser. Nämnas bör ändå att böckerna om Emil på vissa punkter har många likheter med Madickenböckerna. I Emilböckerna åskådliggörs bondesamhällets klasskillnader genom överdådiga bondekalas och fattighjonens elände, och också här tar Lindgren de marginaliserades parti, men samhällskritiken tar sig inte lika starka uttryck som i böckerna om Madicken. Alla de ämnen som traditionellt anses vara tabu i barnlitteratur, samt skolaga, mobbning och barnarov tas upp i Madicken och Junibackens Pims där Lindgren dessutom skoningslöst driver med och ironiserar över överklassen.

Samtidigt råder i böckerna ändå den balans som kännetecknar Lindgrens författarskap. Enligt Jørgen Gaare och Øystein Sjaastad (2002) är Lindgren i första hand en "tabu-författare" i och med att hon både bryter mot normer och tematiserar tabuämnen. Vidare poängterar de vikten av hur man behandlar tabuämnen i barnlitteratur: balansen mellan ljus och mörker bör bevaras, vilket författarna anser Lindgren gör på ett mästerligt sätt. Trots alla de livets skuggsidor som Madicken får tillfälle att reflektera över behåller hon ändå sin livsglädje.

\section{Synligt och osynligt}

Hur har då Astrid Lindgrens ideologi synliggjorts i den amerikanska översättningen av böckerna om Madicken? Allt det som 
klassificeras som tabu i barnlitteratur och som Lindgren tar upp - alkohol, social utsatthet och därigenom utanförskap samt omnämnandet av krig - är närapå imponerande minutiöst och systematiskt censurerat enligt "out of sight, out of mind" - principen. Rent praktiskt har det varit relativt enkelt eftersom kapitlen i Madickenböckerna, trots att de följer årstiderna, kan läsas skilt för sig och det därför, då man läser översättningen, är svårt att upptäcka om ett kapitel, en episod eller en mening har strukits.

Lindgrens brittiska översättare Patricia Crampton som sedan 1970talet översatt bland andra Karlsson på taket, böckerna om Madicken samt Ronja Rövardotter, har i en artikel från 1990 uttalat sig om hur det är att översätta Lindgren, och hur hon varit tvungen att kämpa för att gå emot de rådande översättningsnormerna. Med åren har hon lärt sig att gå emot förläggarens råd om att "så fort du översatt boken, släng originalet och börja på nytt". Crampton vidhåller att om man översätter en riktig författare gör man klokast $i$ att göra precis tvärtemot och inte släppa originalet utom synhåll under hela översättningsprocessen. Att gå emot de rådande översättningsnormerna kräver mod och en stark övertygelse om att man gör rätt - i detta fall vad som är rätt för målgruppen: det läsande barnet.

Den brittiska översättningen av Madicken av Patricia Crampton följer källtexten mer eller mindre ordagrant och inkluderar tabuämnen såsom alkohol, berusning, social ojämlikhet och svordomar. Ordet snor är däremot bannlyst och har alltså strukits då det förekommer skilt för sig, medan det sammansatta ordet snorunge inte har censurerats. Den amerikanska översättningen av Madicken, Mischievous Meg, som utkom 1962 står däremot för det motsatta: allt som kunde tänkas vara "skadligt" för barnet har strukits. Nedan följer några exempel på vad som ändrats eller censurerats i den amerikanska översättningen.

Inledningsvis har Madickens ålder höjts från sju till tio år vilket naturligtvis förorsakar ytterligare ändringar i texten. Troligen har detta gjorts för att den läsande målgruppen skulle vara äldre än sjuårsåldern, och för att undvika att ett yngre barn identifierar sig med Madicken som är både självständig och egensinnig. Å andra sidan kunde man tänka sig att boken på detta sätt når barn som tycker om att läsa om barn i samma ålder eller äldre än de själv, samtidigt som man inte skall förbise den kommersiella aspekten av eventuella större volymer.

Allt det som brukar klassificeras som tabuämnen i barnlitteratur, det vill säga allting som berör alkohol, social ojämlikhet, flickor som svär och/eller slåss samt omnämnandet av krig har strukits i den 
amerikanska måltexten vilket innebär att ord bytts ut och både meningar och stycken samt de facto ett helt kapitel utelämnats. Medan Madickens granne, farbror Nilsson, är full och sover av sig ruset på kökssoffan en lördag eftermiddag både i källtexten och i den brittiska måltexten, får amerikanska barn däremot läsa att han är lat. De får inte heller läsa kapitlet om hur Lisabet pillar in en ärta i näsan (som Vivi Edström kallat det roligaste kapitlet i svensk barnlitteratur), antagligen eftersom socialt relaterade tabuämnen såsom svordomar och slagsmål mellan flickor duggar tätt i kapitlet .Likaså har den del av kapitlet om Junibackens jul där Madicken och Lisabet träffar Mia och Mattis som fått "röa byxer från fattigvården, pilutta er, det har inte ni!" (Lindgren 1960, 157) strukits i den amerikanska måltexten. Uttrycket pilutta er som Lindgren flitigt använder i böckerna om Madicken förekommer för övrigt inte alls i den amerikanska översättningen - kanske för att det är svåröversatt eller har man kanske uppfattat uttrycket som en svordom?

Förutom tabuämnena har utropen och upprepningarna som förmedlar barnets stämningar och känslor "här och nu", och som är så typiska för Lindgrens texter, delvis strukits i den amerikanska översättningen vilket resulterar i en småtrevlig och ytlig berättelse utan dimension och djup.

Med tanke på ovanstående kan det te sig rentav naturligt att en översättning av Madicken och Junibackens Pims aldrig publicerades i USA. I den svenska källtexten förekommer alla de "traditionella" tabuelementen i samtliga kapitel, i olika kombinationer och med betydligt mörkare undertoner än i den första boken om Madicken. Utöver detta får vi läsa om avlusning, slagsmål och skolaga, och ta del av hur tant Nilsson säljer sin kropp till doktor Berglund då utmätning hotar familjen; hon har läst i tidningen att i Stockholm går fattiga människor till lasarettet och säljer sin kropp som doktorerna sedan kan skära i, men inte medan man lever. "Man får flera hundra kronor att ha roligt för medan man lever, och sen får doktorerna kroppen när man är död" ( Lindgren 1976, 46). Också här bibehålls balansen mellan tragik och komik - då farbror Nilsson får höra hur mycket pengar tant Nilsson fått utropar han "250 kronor, bevare oss väl. Det skulle jag aldrig ge för en gammal dö' käring". I kapitlet "Alva på bal" möter Madickens lillasyster Lisabet som älskar ord, också fula ord, borgmästarinnan på torget och utbrister "Titta, där har vi den där fisrumpan" (Lindgren 1976, 170). Detta är upptakten till kapitlet där Lindgren ironiserar över den högfärdiga borgmästarinnan och hennes välgörenhetsbal: "Borgmästarinnan vill att vi ska äta ihop så mycket som möjligt åt de fattiga säjer pappa då de 
satt sig till bords". (Lindgren 1976, 179) och som får ett snöpligt slut med borgmästarinnans sociala "nederlag" i och med att Alva, hembiträdet, och sotaren beundras som kvällens vackraste par. I följande kapitel står självaste borgmästaren i tur att bli förödmjukad och förlöjligad då hans hustru insisterar på att han ska flyga med flygaren som besöker staden. Borgmästaren är rädd, men "borgmästarinnan hon är modig hon! Hon står där så bredbent och vinkar åt honom och ropar så det hörs över hela Kvarnängen: 'Glöm inte göra looping över rådhuset!'". Och borgmästaren gör sin flygtur och sin looping över rådhuset - men inte nog med det, för "han har gjort nånting mer också. Nånting som inte passar sig för borgmästare. Utan bara för små små barn" (Lindgren 1976, 204). Borgmästarparet förekommer endast i Madicken och Junibackens Pims, likaså token Lindkvist som är snäll men "så rysansvärt stark, och ingen vet vad han kan ta sig till, när raseriet kommer på honom" (Lindgren 1976, 64-65). Han gör sig skyldig till försök till barnarov vid två olika tillfällen i boken - första gången är det Lisabet som råkar ut för honom, andra gången är det Madickens och Lisabets nyfödda lillasyster Kajsa.

Förklaringen till varför Lindgren censurerats i USA står delvis att finna i de litterära normer som rådde i USA i början av 1960talet då övergångsperioden mellan traditionella värden å ena sidan och en ny politisk och social medvetenhet å andra sidan inleddes. Efter andra världskriget betonades familjens roll, och den oskuldsfulla, skyddade barndomen hade en stark framtoning i barnlitteraturen i USA (Murray 1998, 176) men ersattes småningom av den såkallade problemromanen som dominerade den litterära scenen genom 1960 och 70-talen. Trots dessa förändringar fortsatte ändå självcensuren bland barnboksförfattarna att blomstra ända till slutet av 1960talet. Utöver detta bör man komma ihåg att en försvinnande liten del av barnlitteratur - omkring en procent - från andra språkområden i världen överhuvudtaget når USA för att översättas.

Av den tidvis väldigt aktiva korrespondens Lindgren förde med sina förläggare och översättare finns en del bevarad i arkiven på Kungliga biblioteket i Stockholm. Trots att det inte finns mycket material tillgängligt som direkt skulle beröra översättningarna av böckerna om Madicken får man ändå en inblick i det pedagogiska klimat som råder i målkulturen (främst USA) under de närmare 40 år korrespondensen täcker. Lindgrens orubbliga princip att barnet alltid står i fokus framkommer tydligt i de brev där hon på ett övertygande sätt motiverar varför hon tar upp kontroversiella ämnen i sina böcker, och framförallt varför hon inte ser på ändringar eller censur med blida ögon. Hur och varför hon godkänt den censurerade 
amerikanska översättningen av den första boken om Madicken samt varför den andra boken aldrig publicerades förblir ändå höljt i dunkel eftersom den korrespondensen (tillsvidare?) saknas i arkiven.

Analysen av den brittiska och den amerikanska översättningen av böckerna om Madicken visar att den brittiska översättningen har, med undantag för ordet snor, inkluderat alla tabuämnen samt allting som berör social ojämlikhet och misär och de problem det för med sig, vilket i sin tur visar att de inte uppfattats som tabu i den brittiska målkulturen. Däremot har alla problem - och därmed också Lindgrens ideologi att inte undanhålla barnet något - sopats under mattan i den amerikanska översättningen av den första boken om Madicken, vilket resulterar i en, i Tourys termer, acceptabel men inadekvat översättning. Den andra boken, Madicken och Junibackens Pims, har osynliggjorts genom att överhuvudtaget inte publiceras i översättning i USA.

Debatten om barnbokscensur går i cykler men har nyligen blossat upp på nytt. Den rikssvenska dagstidningen Svenska Dagbladet citerar i en artikel i mars 2010 chefredaktören på Barnens Bokklubb som bekräftar att utmanande barnböcker inte säljer bra: "Man vill inte oroa barnen, det får inte vara något farligt och helst inte för mycket magi för 'det finns ju inte i verkligheten'”. Kanske detta kan ses som en motreaktion av föräldrar som växte upp med realistiska berättelser på 1970-talet? Eller bottnar behovet att censurera barnböcker i något så allmänmänskligt och primitivt som rädsla? Denna rädsla kan härröra sig från den vuxnes oförmåga att ta upp och diskutera svåra frågor, eller i rädsla för obekväma frågor, eller möjligtvis rädsla för att förlora kontrollen och därmed makt och auktoritet över barnet. Genom att eliminera svåra och svårbegripliga element ur en berättelse fråntar de vuxna auktoriteterna sig ansvaret och "besväret" att förklara för och diskutera tillsammans med barnet. Samtidigt berövas barnet rätten att ställa frågor och att fundera på sådant som finns utanför dess egen ombonade verklighet men som icke desto mindre existerar, och därigenom förmågan att känna empati. Genom att skyddas från allt ont förblir barnet till syvende och sidst ett oskyddat och känslomässigt övergivet barn som i värsta fall växer upp till en trångsynt vuxen som censurerar barnböcker... Och det är svårt att tro att det var det Lindgren avsåg då hon skrev böckerna om Madicken.

Biografisk information: Angelika Nikolowski-Bogomoloff är doktorand vid Institutionen för moderna språk vid universitetet $i$ Helsingfors. Hennes forskning fokuserar på ideologiska dimensioner $i$ de amerikanska, brittiska och tyska översättningarna av Astrid Lindgrens Madicken och Madicken och Junibackens Pims. Kontakt: nikolows@mappi.helsinki.fi 


\section{Bibliografi}

Chesterman, Andrew. Memes of translation: the spread of ideas in translation theory. Amsterdam/Philadelphia: John Benjamins Publishing Company, 1997.

Crampton, Patricia. "Translating Astrid Lindgren". I Swedish book review, supplement on children's literature (1990): 83-86.

Gaare, Jørgen och Sjaastad, Øystein. Pippi och Sokrates: filosofiska vandringar i Astrid Lindgrens värld. Stockholm: Natur och Kultur, 2002.

Hermans, Theo. "Translation norms and correct translations". I Translation studies: the state of the art edited by Kitty M. van Leuven-Zwart \& Ton Naaijkens. Amsterdam: Rodopi, 1991, s. 155-169.

Hollindale, Peter. "Ideology and the children's book". I Hunt, Peter. Literature for children. London/New York: Routledge, 1992, s. 19-40.

Lindgren, Astrid. Madicken. Stockholm: Raben \& Sjögren, 1960.

Lindgren, Astrid. Mischievous Meg. Translated by Gerry Bothmer. New York: Viking Press, 1962.

Lindgren, Astrid. Madicken och Junibackens Pims. Stockholm: Raben \& Sjögren, 1976.

Lindgren, Astrid. Mardie's adventures. Translated by Patricia Crampton. London: Methuen Children's Books Ltd, 1979.

Lindgren, Astrid. Mardie to the rescue. Translated by Patricia Crampton. London: Methuen Children's Books, 1981.

Murray, Gail Schmunk. American children's literature and the construction of childhood. New York: Twayne's Publishers, 1998.

Oittinen, Riitta. I am me - I am other: on the dialogics of translating for children. University of Tampere: Tampere, 1993.

Puurtinen, Tiina. "Dynamic style as a parameter of acceptability in translated children's books". I Translation studies: an interdiscipline edited by Snell-Hornby M., Pöchhacker F. och Kaindl K. Amsterdam: John Benjamins, 1994.

O'Sullivan, Emer. Comparative children's literature. London and New York: Routledge, 2005.

Strömstedt, Margareta. Astrid Lindgren: en levnadsteckning. Stockholm: Raben \& Sjögren, 2003.

Tabbert, Reinbert. "Approaches to the translation of children's literature: a review of critical studies since 1960". Target 14 (2002) 2: 303-351.

Thomson-Wohlgemuth, Gabriele. "Children's literature and translation under the east German regime". Meta 48 (2003) 1-2: 241-249.

Toury, Gideon. Descriptive translation studies and beyond. Amsterdam \& Philadelphia: John Benjamins, 1995.

Note: This article is being published simultaneously in Barnboken - tidskrift för barnlitteraturforskning/Journal of Children's Literature Research and Nordic ChildLit Aesthetics/Barnelitterært forskningstidsskrift 